\title{
Treatment of relapsed refractory multiple myeloma: which new PI-based combination treatments do patients prefer?
}

This article was published in the following Dove Press journal: Patient Preference and Adherence

\author{
Thomas Wilke' \\ Sabrina Mueller ${ }^{2}$ \\ Sabine Bauer ${ }^{2}$ \\ Silvia Pitura ${ }^{3}$ \\ Leona Probst ${ }^{3}$ \\ Boris A Ratsch ${ }^{3}$ \\ Hans Salwender ${ }^{4}$ \\ 'Institut für Pharmakoökonomie und \\ Arzneimittellogistik (IPAM), 23966 \\ Wismar, Germany; ${ }^{2}$ Ingress-Health, \\ 23966 Wismar, Germany; ${ }^{3}$ Takeda \\ Pharma Vertrieb GmbH \& Co. KG, \\ I0II7 Berlin, Germany; ${ }^{4}$ Asklepios \\ Kliniken Hamburg GmbH, 22763 \\ Hamburg, Germany
}

Correspondence: Thomas Wilke Institut für Pharmakoökonomie und Arzneimittellogistik (IPAM), Alter Holzhafen 19, 23966 Wismar, Germany Tel +49384I 7581014

Email thomas.wilke@ipam-wismar.de
Background and objectives: This study describes preferences of German relapsed refractory multiple myeloma (RRMM) patients with novel proteasome inhibitor-based combination treatments.

Methods: Patients with a minimum age of 18 years and a diagnosis of RRMM were included. Their preferences were assessed using a discrete choice experiment design, which was developed based on a literature review and two patient focus group discussions. The final discrete choice experiment design consisted of four attributes, namely "therapy application regimen," "time without progression of disease," "possibility of grade $\geq 3$ adverse events (AEs) affecting the blood," and "possibility of grade $\geq 3$ AE heart failure."

Results: Analysis was based on 84 patients (36.9\% females, mean age 62.7 years, mean multiple myeloma disease duration 5.5 years). Among the tested attributes, "therapy application regimen" was assigned the highest importance for treatment decisions (38.8\%), the second important attribute was "time without progression of disease" (38.7\%), followed by "possibility of AE heart failure" (13.9\%) and "possibility of AEs affecting the blood" (8.6\%). Patients preferred oral intake once a day and once a week over other application modes such as oral intake once a day and once a week plus twice-weekly infusions. Furthermore, they preferred longer disease progression-free time and lower risk of grade $\geq 3$ AEs. The highest overall utility was derived for ixazomib + lenalidomide + dexamethasone (utility: 3.218 ), compared with lenalidomide + dexamethasone (2.769), and carfilzomib + lenalidomide + dexamethasone (1.928).

Conclusion: RRMM patients prefer treatments with an all-oral application, a longer diseaseprogression-free time, and a lower probability of AEs. If patients face tradeoffs, they accept a lower progression-free time and/or higher AE rates to get an all-oral therapy.

Keywords: MM patient's treatment preferences, relapsed refractory multiple myeloma, RRMM, discrete choice experiment, DCE

\section{Introduction}

Immunomodulatory agents and proteasome inhibitors (PIs) such as bortezomib ${ }^{1,2}$ have led to an improvement of overall survival (OS) and health-related quality of life for relapsed refractory multiple myeloma (RRMM) patients and are a cornerstone of modern RRMM therapy. Treatments available or currently under development belonging to a new generation of PIs are, for example, carfilzomib, marizomib, oprozomib, or ixazomib, ${ }^{3-5}$ whereas the latter represents the first PI that is administered orally. ${ }^{5}$

Overall, when considering a therapy in a shared decision-making framework, treatments should be tailored as much as possible to the needs of the patients. Low acceptance of treatments by patients might be linked to a low treatment adherence 
and/or early treatment discontinuation due to patients' decisions and, finally, poorer OS. ${ }^{6}$ Therefore, it is important to collect reliable and valid data on patient preferences when providing therapies.

None of the previous patient preference studies in multiple myeloma (MM) addressed RRMM patients in particular and/or triple combination therapies. ${ }^{7-11}$ However, RRMM patient preferences may differ considerably compared with newly diagnosed MM patient preferences, due to different treatment options available such as double/triple combination regimens, a higher number of treatment lines patients already experienced, longer disease duration, potential disappointments about previous treatment failure(s), or older age. Consequently, the objective of this study was to assess RRMM patient preferences with regard to selected new generation PI-based combination treatment options.

\section{Methods}

RRMM treatment options may be characterized by various characteristics (attributes) such as efficacy, safety, or treatment burden, which often require trade-off decisions of both physicians and patients. A discrete choice experiment (DCE) is a stated preference elicitation method that requires the respondents to evaluate such trade-offs when deciding about different treatment options, each consisting of numerous attributes, as it needs to be done in reality. ${ }^{12}$ The basic assumption of a DCE is that rational individuals will always choose alternatives with higher levels of expected utility. This study, which is the first study using a DCE framework to assess RRMM patients' treatment preferences, followed a two-stage design, according to recommendations how to conduct DCE studies in health care. ${ }^{12}$ In stage 1, a targeted review was conducted to generate a first list of potential attributes and respective attribute levels describing different PI-based RRMM combination treatment options. Here, summary of product characteristics, clinical trial data, as well as previously performed preference studies in MM were analyzed. With regard to adverse event (AE)-related attributes, only grade $\geq 3$ AEs were taken into account as these are typically reducing the quality of life of patients most severely and are reported more consistently across different trials.

The whole list of attributes was presented to patients and discussed with them in two qualitative focus group discussions (FGDs). After a general discussion about potential additional attributes to be included, importance of each attribute was assessed by means of a dual questioning technique. $^{13}$
Based on the final list of attributes, a factorial DCE design was generated (hypothetical choice sets). An additional choice set was added in which one previous choice set was doubled, in order to assess the consistency of a patient's response behavior. Finally, all choice sets were graphically visualized (choice cards) to facilitate the comprehensibility of the different attributes and attribute levels.

Patients were recruited in two different ways: 1) via German patient support groups (PSGs) and 2) via physician practices within Germany. The inclusion criteria for survey participants were defined as follows:

- Diagnosis of RRMM (please note that in case of patients included via PSGs, this information was obtained from the patient).

- Minimum age of 18 years.

- Ability and willingness to take part in an interview.

To collect DCE data, study patients were interviewed in stage 2 by trained interviewers, either face-to-face or via telephone. All phone interview patients received a postal mailing with the prepared choice cards and a brief description of the next steps.

Data analysis was only conducted for patients with consistent DCE data, based on the responses to the above-described test choice set. ${ }^{14}$ DCE data were analyzed using conditional logit regression models. The influence of different attribute levels on the probability of a patient's decision to choose a specific alternative as well as respective utility levels was estimated, considering interaction effects between attributes. Calculated utility levels were also applied to selected novel PI-based RRMM combination treatments. Analyses were done with Stata/MP 14 and Microsoft Excel 2016.

The study protocol was approved by the independent Ethics Committee of the Medical Faculty at the University of Rostock. The study was conducted in accordance with the Declaration of Helsinki. Participants provided written informed consent prior to their enrollment in the study.

\section{Results FGDs and final DCE design}

In our targeted PubMed-based literature review, we identified 42 publications (Figure S1 for search strings and PRISMA chart); additionally, product characteristics of addressed agents were reviewed. Based on this review, 13 different attributes were discussed with eight RRMM patients in the FGDs (two FGDs with four patients each): progression-free survival; possible side effects: occurrence of thrombocytopenia, neutropenia, anemia, hypokalemia, cardiac failure, hypertension, ischemic heart disease, fatigue, diarrhea, renal 
failure, rash; application of therapy. The dual questioningranking of these attributes resulted in the following seven topranked attributes (in that order): anemia as AE, time without progression of disease, neutropenia as $\mathrm{AE}$, thrombocytopenia as AE, application mode of the treatment including number and duration of necessary physician visits, hypokalemia, and heart failure as AEs. The ranking showed that the four most relevant safety attributes were all connected to bloodrelated side effects. To reduce the number of attributes (and in this respect to optimize the DCE design), it was decided to merge these attributes to one overall attribute, defined as "possibility of AEs affecting the blood."

Consequently, four attributes were used to generate the experimental design. To confront patients with realistic, although hypothetical choices, treatment-associated attribute levels were derived from either the SmPCs (application mode) or data reported in the respective clinical trials addressing new generation PIs (progression-free time and the MIN and MAX grade $\geq 3 \mathrm{AE}$ frequencies). ${ }^{1,3}$ In the final DCE design, the following attributes/attribute levels were included: "therapy regimen/drug administration": 1) oral intake once daily plus once per week with 2-hour physician visit once per month; 2) oral intake once daily plus twice per week with 2-hour physician visit once per month; 3 ) oral intake once daily plus once per week plus 3- to 4-hour physician visits twice per week including administration of one infusion per visit; "time without progression of disease": 1) 17 months, 2) 20 months, 3) 26 months; "possibility of grade $\geq 3$ AEs affecting the blood": 1) 12 of 100 patients, 2) 19 of 100 patients; "possibility of grade $\geq 3$ AEs in regard to heart failure": 1) two of 100 patients, 2) four of 100 patients. The final DCE design consisted of ten choice sets. In each of the choice sets, the patient needed to decide between two different hypothetical treatment options (Figure 1: one example choice set).

\section{Quantitative DCE survey}

One hundred thirteen RRMM patients could be included in the study. Thirteen patients withdrew their informed consent after study inclusion or an interview appointment could not be made. Of the remaining 100 patients, 16 (16.0\%) did not answer consistently and were thus excluded from all further analyses. Consequently, final analyses were carried out for 84 patients. Mean age of patients in the final analysis sample was 62.8 years, $36.9 \%$ were female, mean/median disease duration was 5.5/4.2 years, and the majority of patients had either an Eastern Cooperative Oncology Group (ECOG) performance status of $1(45.2 \%)$ or $2(35.7 \%)$ (Table 1$)$; $83.3 \%$ of the included patients already received a stem cell transplantation, and patients included via study sites, in comparison with those included via PSGs, were generally older and more female (Table 1).

Preference analysis was based on 756 different hypothetical treatment choices (nine decisions for each of the 84 patients). The attribute "therapy regimen/drug administration" influenced patients' decisions with an extent of $38.8 \%$. "Time without progression of disease" was almost equally important with an influence of $38.7 \%$, whereas the attributes "possibility of side effect heart failure" with $13.9 \%$ influence and "possibility of side effects affecting the blood" with $8.6 \%$ influence were less important (Figure 2). Preferences observed in the total study population were widely consistent across subgroups according to age, gender, disease duration, and traveling distance to treating physician (Table S1).

Generally, utilities differed significantly between all tested attribute levels within the four attribute categories (Figure 2). So, for example, a treatment associated with 26-month progression-free time instead of 17 months was associated with an additional utility of 1.785 , whereas oral intake once daily plus once weekly instead of oral intake once daily/once weekly plus an additional twice-weekly physician visit and infusion was associated with an additional utility of 1.794. Lower frequencies of grade $\geq 3$ AEs were associated with positive utilities as well, although these were considerably lower, compared with the previously described attributes (Figure 2).

Table 2 shows the utilities as derived for the studied new generation PI-based combination regimens; utilities were derived from the sum of the attribute-level-specific utilities applicable for the respective treatment options: 1) carfilzomib plus lenalidomide plus dexamethasone (CRd), 2) ixazomib plus lenalidomide plus dexamethasone (IRd), and 3) lenalidomide plus dexamethasone ( $\mathrm{Rd}$ ). Total utilities associated with these treatments were calculated based on the median progression-free survival time as reported in the respective trials (17.6, 20.6, or 26.3 months, respectively), the respective application mode $(1,2$, or 3$)$, and the respective risk to experience severe AEs with respect to heart failure $(2 \%$ or $3.8 \%$ ) and blood-related side effects (ranging from 1.1\% to $29.6 \%$ ), as described in the respective clinical trials. ${ }^{3,5}$ Because the attribute "possibility of side effects affecting the blood" was a composite attribute (including thrombocytopenia, neutropenia, anemia, and hypokalemia), three scenarios were calculated: minimum AE risk, maximum risk, and mean AE risk across the four different grade 3+ AEs belonging to this category. When considering the mean values in this respect, highest utility for patients arose from 


\section{Please decide: which of the treatment options would you prefer?}

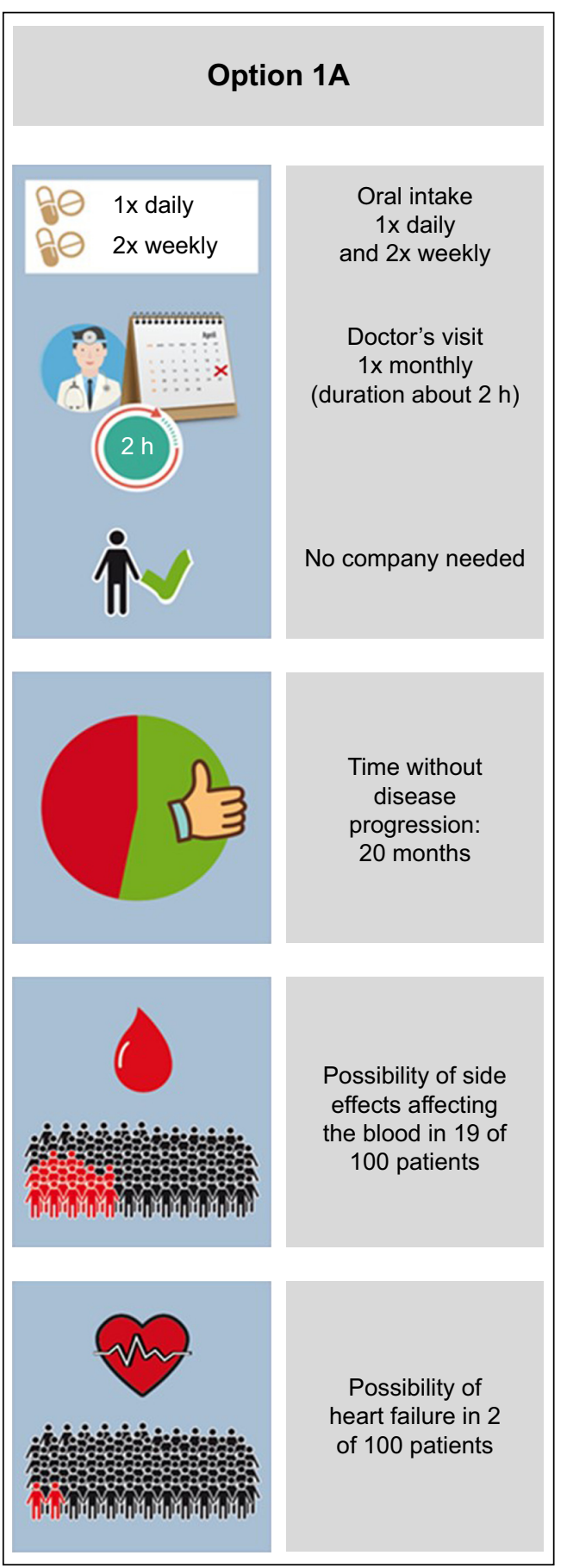

Figure I Example of a visualized choice card.

the treatment option IRd (3.218), followed by Rd (2.769) and CRd (1.928).

In a post hoc analysis, the length of progression-free time in months was calculated that patients would be willing to

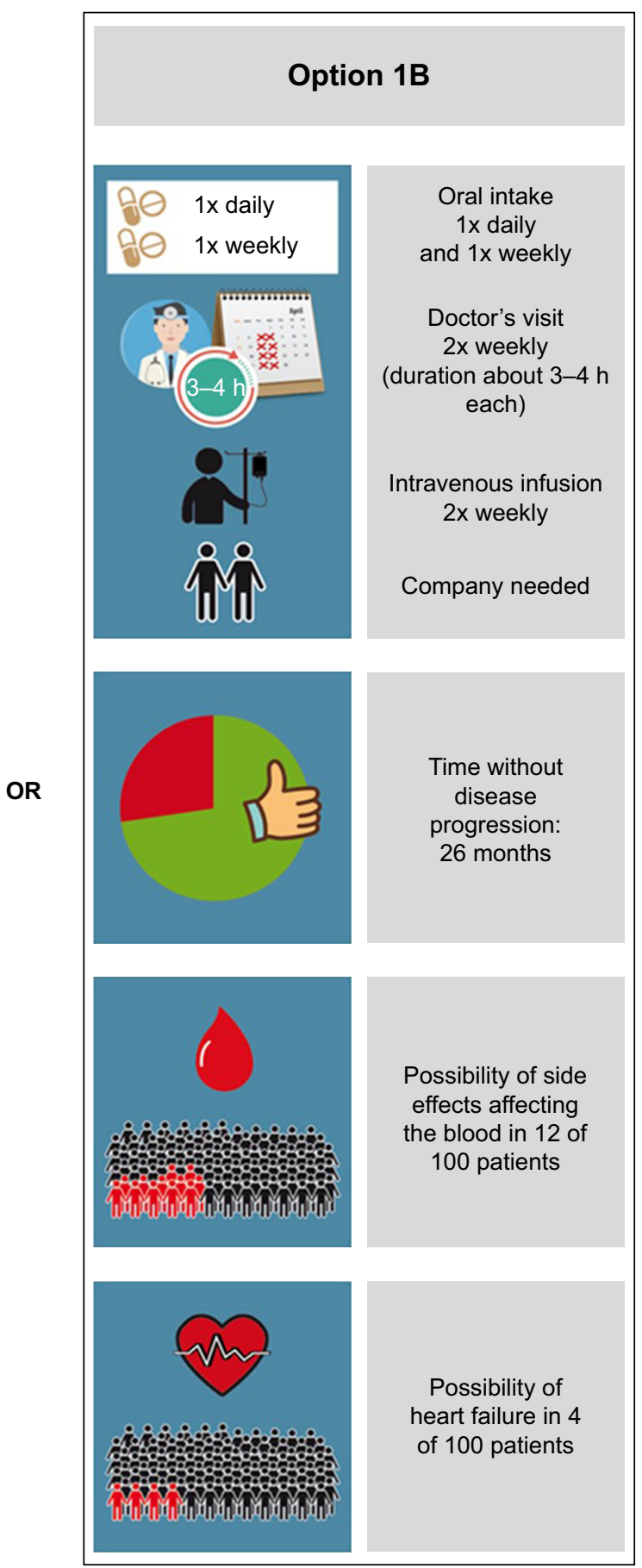

"trade" to receive a certain attribute combination as treatment. Results show that patients would be willing to give up the highest number of progression-free months for treatment options incorporating all-oral application and/or lower probability 
Table I Patient characteristics

\begin{tabular}{|c|c|c|c|c|}
\hline Characteristics & $\begin{array}{l}\text { Patients included } \\
\text { in the DCE } \\
\text { analyses }\end{array}$ & $\begin{array}{l}\text { Patients recruited } \\
\text { via PSGs } \\
\text { (included for } \\
\text { analyses) }\end{array}$ & $\begin{array}{l}\text { Patients recruited } \\
\text { via study sites } \\
\text { (included for } \\
\text { analyses) }\end{array}$ & $\begin{array}{l}\text { Patients with } \\
\text { inconsistent } \\
\text { DCE answers } \\
\text { (not included in } \\
\text { analyses) }\end{array}$ \\
\hline $\mathrm{N}$ & 84 & 67 & 17 & 16 \\
\hline Female gender $(\%)$ & $31(36.9)$ & $24(35.8)$ & $7(4 \mid .2)$ & $8(50.0)$ \\
\hline Age in years, mean (median/SD) & $62.8(63.5 / 9.7)$ & $61.4(62.0 / 9.5)$ & $68.1(68.0 / 8.6)$ & $67.8(65.0 / 10.3)$ \\
\hline Disease duration in years, mean (median/SD) & $5.5(4.2 / 4.3)$ & $5.6(4.3 / 4.5)$ & $5.2(3.7 / 3.8)$ & $6.2(4.9 / 4.8)$ \\
\hline \multicolumn{5}{|l|}{ Living situation, $\mathrm{n}(\%)$} \\
\hline Patients living alone & II (13.1) & $8(11.9)$ & $3(17.7)$ & $5(31.3)$ \\
\hline Patients living together with a spouse/partner & $70(83.3)$ & $56(83.6)$ & $14(82.4)$ & $10(62.5)$ \\
\hline Patients living together with children/others & $3(3.6)$ & $3(4.5)$ & $0(0.0)$ & $\mathrm{I}(6.3)$ \\
\hline \multicolumn{5}{|l|}{ Educational status, n (\%) } \\
\hline Untrained & $\mathrm{I}(\mathrm{I} .2)$ & $0(0.0)$ & I (5.9) & I (6.3) \\
\hline Apprenticeship & $29(34.5)$ & $21(31.3)$ & $8(47.1)$ & II (68.8) \\
\hline University & $26(31.0)$ & $26(38.8)$ & $0(0.0)$ & I (6.3) \\
\hline Others & $28(33.3)$ & $20(23.8)$ & $8(47.1)$ & $3(18.8)$ \\
\hline \multicolumn{5}{|l|}{ Employment status, n (\%) } \\
\hline Full time & $7(8.3)$ & $7(10.4)$ & $0(0)$ & $0(0.00)$ \\
\hline Part time & $8(9.5)$ & $7(10.4)$ & $I(5.9)$ & $I(12.5)$ \\
\hline Unable to work & $10(11.9)$ & $9(13.4)$ & I (5.9) & $2(6.3)$ \\
\hline Retired & $50(59.5)$ & $36(53.7)$ & $14(82.4)$ & $12(81.3)$ \\
\hline Others & $9(10.7)$ & $8(11.9)$ & I (5.9) & $0(0.00)$ \\
\hline \multicolumn{5}{|l|}{$\begin{array}{l}\text { Ways in which patients get to their } \\
\text { RRMM-treating physician, } \mathrm{n}(\%)\end{array}$} \\
\hline Public transportation & $9(10.7)$ & $9(13.4)$ & $0(0.00)$ & $3(25.0)$ \\
\hline Car & $45(53.6)$ & $40(59.7)$ & $5(29.4)$ & $6(37.5)$ \\
\hline Patient is taken by friends/family & $10(11.0)$ & $8(11.9)$ & $2(11.8)$ & $4(18.8)$ \\
\hline Others & $20(23.8)$ & $10(14.9)$ & $10(58.8)$ & $3(18.8)$ \\
\hline $\begin{array}{l}\text { Distance to physician who treats RRMM in km, } \\
\text { mean (median/SD) }\end{array}$ & $37.2(15.0 / 61.7)$ & $43.2(15.0 / 67.6)$ & $13.6(13.0 / 10.4)$ & $27.9(19.0 / 26.1)$ \\
\hline $\begin{array}{l}\text { Travel time to physician who treats RRMM in } \\
\text { minutes, mean (median/SD) }\end{array}$ & $39.4(30.0 / 40.4)$ & $44.1(30.0 / 43.8)$ & $20.9(20.0 / 10.5)$ & $33.8(30.0 / 17.2)$ \\
\hline $\begin{array}{l}\text { Patients who received a treatment for RRMM at the } \\
\text { time of interview, } n(\%)\end{array}$ & $55(65.5)$ & $42(62.7)$ & $13(76.5)$ & $8(50.0)$ \\
\hline $\begin{array}{l}\text { Patients who already have experience with } \\
\text { intravenous medication, } n(\%)\end{array}$ & $83(98.8)$ & $66(98.1)$ & $17(100.0)$ & $14(87.0)$ \\
\hline \multicolumn{5}{|l|}{$\begin{array}{l}\text { Patients experienced the intravenous application } \\
\text { as ..., } \mathrm{n}(\%)\end{array}$} \\
\hline$\ldots$ very stressful & $7(8.3)$ & $5(7.5)$ & $2(11.8)$ & $0(0.0)$ \\
\hline ... stressful & $21(25.0)$ & $19(28.4)$ & $2(11.8)$ & $5(28.6)$ \\
\hline$\ldots$ less stressful & $28(33.3)$ & $22(32.8)$ & $6(35.3)$ & $7(57.1)$ \\
\hline ... hardly stressful & $27(32.1)$ & $20(29.9)$ & $7(4 I .2)$ & $2(14.3)$ \\
\hline $\begin{array}{l}\text { Patient-reported average duration of an } \\
\text { intravenous medication application in minutes, } \\
\text { mean (median/SD) }\end{array}$ & I0I.I (90.0/64.0) & $105.8(90.0 / 67.8)$ & $85.3(90.0 / 46.2)$ & $96.8(90.0 / 51.1)$ \\
\hline $\begin{array}{l}\text { Patients who received a stem cell } \\
\text { transplantation, } \mathrm{n}(\%)\end{array}$ & $70(83.3)$ & $58(86.6)$ & $12(70.6)$ & $10(62.5)$ \\
\hline
\end{tabular}


Table I (Continued)

\begin{tabular}{|l|l|l|l|l|}
\hline Characteristics & $\begin{array}{l}\text { Patients included } \\
\text { in the DCE } \\
\text { analyses }\end{array}$ & $\begin{array}{l}\text { Patients recruited } \\
\text { via PSGs } \\
\text { (included for } \\
\text { analyses) }\end{array}$ & $\begin{array}{l}\text { Patients recruited } \\
\text { via study centers } \\
\text { (included for } \\
\text { analyses) }\end{array}$ & $\begin{array}{l}\text { Patients with } \\
\text { inconsistent } \\
\text { DCE answers } \\
\text { (not included in } \\
\text { analyses) }\end{array}$ \\
\hline $\begin{array}{l}\text { ECOG-performance scale at the time of } \\
\text { interview, } \mathrm{n}(\%)\end{array}$ & & & \\
\hline Grade 0 & $\mathrm{II}(13.1)$ & $9(13.4)$ & $2(11.8)$ & $3(18.8)$ \\
\hline Grade I & $38(45.2)$ & $26(38.8)$ & $12(70.6)$ & $6(37.5)$ \\
\hline Grade 2 & $30(35.7)$ & $27(40.3)$ & $3(17.7)$ & $5(31.3)$ \\
\hline Grade 3 & $5(6.0)$ & $5(7.5)$ & $0(0.0)$ & $2(12.5)$ \\
\hline Grade 4 & $0(0.0)$ & $0(0.0)$ & $0(0.0)$ & $0(0.0)$ \\
\hline
\end{tabular}

Notes: Patient characteristics at the time of study inclusion are described. Characteristics of patients included in the final data analysis ( $n=84$ ) with the respective subgroups of patients included via PSGs or study sites are shown. Moreover, characteristics of patients excluded from the final analysis set due to inconsistent DCE response behavior $(n=16)$ are shown.

Abbreviations: DCE, discrete choice experiment; ECOG, Eastern Cooperative Oncology Group; PSGs, patient support groups; RRMM, relapsed refractory multiple myeloma.

of side effects. As an example, in order to receive an all-oral instead of an oral plus twice-weekly infusion therapy regimen combined with lower AE risk risks in regard to blood-related events and heart failure, RRMM patients would be willing to trade up to 14.4 months of progression-free time (Table S2).

\section{Discussion}

Our study shows that, when deciding on treatment options among hypothetical novel PI-based combination treatments that are characterized by the tested four attributes, patients ranked the attribute "therapy regimen/drug administration" as the most important, closely followed by "time without progression of disease." With regard to the therapy regimen, patients preferred application regimens based on an all-oral intake of drugs instead of lengthy infusions in physician's practices, so that they take into account the effects of a therapy on their quality of life.

One of the main strengths of a DCE analysis is that different characteristics of specific treatments (here: attribute levels) can be transferred into utilities and, finally, overall

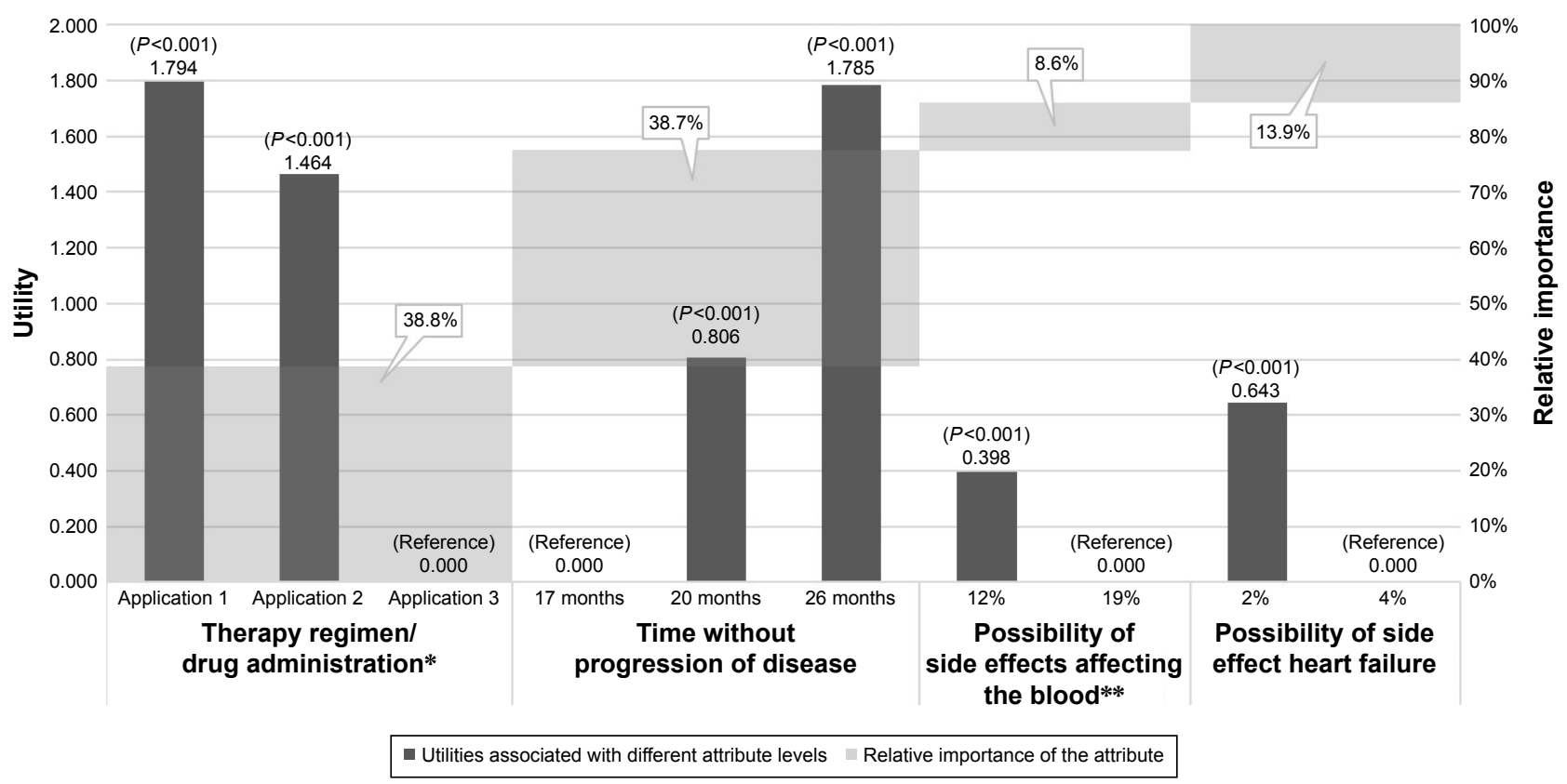

Figure 2 Relative importance of different treatment attributes and utilities of different treatment attribute levels, based on conditional logit regression analysis of the discrete choice experiment data.

Notes: *Application I describes the following therapy regimen/drug administration: oral intake once daily and once per week; physician visit once per month with a duration of approximately 2 hours; patient does not need to be accompanied; Application 2 describes the following therapy regimen/drug application: oral intake once daily and twice per week; physician visit once per month with a duration of approximately 2 hours; patient does not need to be accompanied; Application 3 describes the following therapy regimen/drug application: oral intake once daily and once per week; physician visit twice per week, including administration of one infusion per visit, with a duration per visit of approximately 3-4 hours; patient needs to be accompanied. **This attribute includes thrombocytopenia, neutropenia, anemia and hypokalemia. 
Table 2 Utilities of different overall treatment options

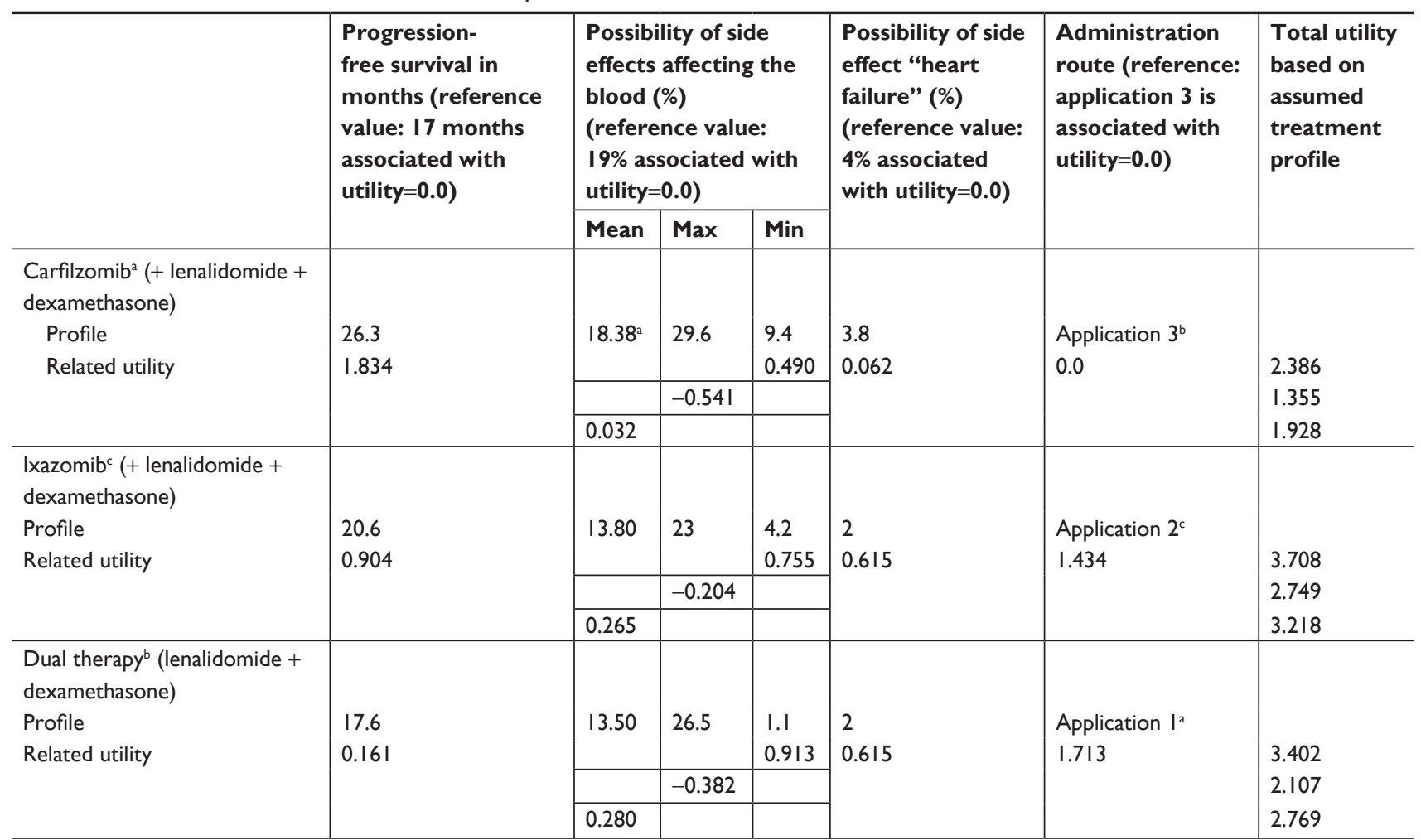

Notes: a Treatment option described by the following attributes: progression-free survival of 26.3 months, mean possibility of side effects $\geq$ grade 3 affecting the blood (including hypokalemia with $9.4 \%$, neutropenia with $29.6 \%$, thrombocytopenia with $16.6 \%$, anemia with $17.9 \%$ ) of $18.375 \%$, possibility of heart failure ( $\geq$ grade 3 ) of 3.8 , and application regimen 3 (oral intake once daily and once per week; physician visit twice per week, including administration of one infusion per visit, with a duration per visit of approximately 3-4 hours; the patient needs to be accompanied). ${ }^{3}$ 'Treatment option described by the following attributes: progression-free survival of I7.6 months, mean possibility of side effects $\geq$ grade 3 affecting the blood (including hypokalemia with I.1\% [5]/4.9\% [3], neutropenia with 24.0\% [5]/26.5\% [3], thrombocytopenia with 9.0\% [5]/I2.3\% [3], anemia with 13.0\% [5]/I7.2\% [3]) of I3.50\%, possibility of heart failure ( $\geq$ grade 3 ) of $2.0 \%$, and application regimen I (oral intake once daily and once per week; physician visit once per month with a duration of approximately 2 hours; the patient does not need to be accompanied). ${ }^{3,5}$ cTreatment option described by the following attributes: progression-free survival of 20.3 months, mean possibility of side effects $\geq$ grade 3 affecting the blood (including hypokalemia with $4.2 \%$, neutropenia with $23.0 \%$, thrombocytopenia with $19.0 \%$, anemia with $9.0 \%$ ) of $13.80 \%$, possibility of heart failure ( $\geq$ grade 3 ) of $2.0 \%$, and application regimen 2 (oral intake once daily and twice per week; physician visit once per month with a duration of approximately 2 hours; the patient does not need to be accompanied). ${ }^{5}$

utilities for complete treatment options can be derived. These take into account trade-offs patients make during their decisions. Among the tested treatments, an IRd treatment showed the highest utility, if compared with Rd or CRd. Utility values per attribute level can also be applied to other treatments, as long as these can be described by the four tested attributes in the study presented.

As far as the authors of this study are aware, five published studies so far dealt with patient preferences in MM. ${ }^{7-11}$ In terms of methodology (number and type of attributes tested, patient inclusion criteria, sample size, preference elicitation technique, multicenter vs single center), there are substantial differences between these studies which make it challenging to compare their results with those of our analysis. Three studies assessed patient preferences based on a DCE methodology. ${ }^{7,8,11}$ These studies confirmed, as our study did, that MM patients are able to express treatment preferences, even if different treatments are associated with specific advantages/disadvantages. Moreover, these studies, as our study, confirmed that patients are more interested in a higher efficacy compared with safety. Our study differs from other studies in the fact that it addressed RRMM patients only and that it showed a higher importance of the application mode of the therapy than previous studies did.

\section{Limitations}

We acknowledge some limitations of our study. The design of the DCE used in this study consisted of complex attributes. Appropriate measures had been taken to increase userfriendliness, understandability, and convenience of the DCE choice sets. Nevertheless, it cannot completely be excluded that patients might have had difficulties in understanding the different treatment options presented on the choice cards.

Inclusion of all attributes describing the different RRMM treatment options was not possible because this would have resulted in too many choice cards. Only attributes ranked as most important in FGDs were selected for the DCE choice cards. However, both attributes in regard to blood-related AEs 
and different aspects of drug application (frequency, necessity to visit physicians) were shown to patients as one respective attribute ("possibility of side effects affecting the blood," "therapy regimen/drug administration"), so that a broader range of aspects of therapy options could be incorporated. This method may have led to an underrating of the importance of the single components of these attributes. Furthermore, it is highly probable that OS is also an attribute that would matter from a patient's perspective. However, as it was the aim to compare new PI-based treatments and OS data were not available in sufficient maturity for these treatments at the time of the data collection, we needed to exclude this attribute. Nevertheless, in our view progression-free time is a very important outcome in MM as progression is often accompanied by bone pain and/ or kidney failure, which reduces the quality of life of patients substantially. Additionally, as we aimed to present our patients easy to understand treatment choices, we used progression-free time as an attribute instead of the more difficult to understand outcome progression-free survival. We acknowledge that there exist differences in the definition of these outcomes. Moreover, due to the design of the study and associated data collection, we were not able to assess the current and previous treatment of interviewed patients. Both current and previous treatments might have influenced patients' DCE responses. Finally, we included 67 out of 84 patients via PSGs, and their RRMM diagnosis was self-reported and thus, to a certain degree, uncertain. However, as $86.6 \%$ of them reported to have received a stem cell transplantation, we see a high probability that these patients indeed suffered from RRMM.

\section{Conclusion}

Because RRMM treatment options are constantly evolving and differ from each other in several attributes, it is important to investigate the preferences of patients in that respect. Our study shows that RRMM patients prefer effective and safe treatments, but are willing to accept a lower progression-free time if this is associated with an all-oral application mode of the therapy.

\section{Acknowledgments}

The authors would like to thank all patient support groups, all study sites, and especially all patients that supported this study. Moreover, they would like to thank two reviewers for their valuable comments. This work was supported by Takeda Pharma Vertrieb GmbH \& Co. KG.

\section{Disclosure}

TW has received honoraria from several pharmaceutical/ consultancy companies, eg, Novo Nordisk, Abbvie; Merck;
GSK, BMS, LEO Pharma, Astra Zeneca, Bayer, Boehringer Ingelheim, Pharmerit. SM and SB participated in this study as a staff member of Ingress-health; the work of Ingresshealth in this study was sponsored by Takeda Pharma Vertrieb GmbH \& Co. KG. SP, LP, and BAR are employees of Takeda Pharma Vertrieb GmbH \& Co. KG. HS received consultancy fees, project funding, and reimbursement of travel costs from different pharmaceutical companies, such as Celgene, Janssen-Cilag, Novartis, BMS, Amgen, Takeda. The authors report no other conflicts of interest in this work.

\section{References}

1. Merz M, Salwender H, Haenel M, et al. Subcutaneous versus intravenous bortezomib in two different induction therapies for newly diagnosed multiple myeloma: an interim analysis from the prospective GMMG-MM5 trial. Haematologica. 2015;100(7):964-969.

2. Cornell RF, Kassim AA. Evolving paradigms in the treatment of relapsed/refractory multiple myeloma: increased options and increased complexity. Bone Marrow Transplant. 2016;51(4):479-491.

3. Stewart AK, Rajkumar SV, Dimopoulos MA, et al. Carfilzomib, lenalidomide, and dexamethasone for relapsed multiple myeloma. $N$ Engl J Med. 2015;372(2):142-152.

4. Kubiczkova L, Pour L, Sedlarikova L, Hajek R, Sevcikova S. Proteasome inhibitors - molecular basis and current perspectives in multiple myeloma. J Cell Mol Med. 2014;18(6):947-961.

5. Moreau P, Masszi T, Grzasko N, et al. Oral Ixazomib, Lenalidomide, And Dexamethasone For Multiple Myeloma. N Engl J Med. 2016; 374(17):1621-1634.

6. Hari P, Romanus D, Palumbo A, et al. Prolonged Duration of Therapy Is Associated With Improved Survival in Patients Treated for Relapsed/ Refractory Multiple Myeloma in Routine Clinical Care in the United States. Clin Lymphoma Myeloma Leuk. 2018;18(2):152-160.

7. Mühlbacher AC, Nübling M. Analysis of physicians' perspectives versus patients' preferences: direct assessment and discrete choice experiments in the therapy of multiple myeloma. Eur J Health Econ. 2011; 12(3):193-203.

8. Mühlbacher AC, Lincke HJ, Nübling M. Evaluating patients' preferences for multiple myeloma therapy, a Discrete-Choice-Experiment. Psychosoc Med. 2008;5:Doc10.

9. Barbee MS, Harvey RD, Lonial S, et al. Subcutaneous versus intravenous bortezomib: efficiency practice variables and patient preferences. Ann Pharmacother. 2013;47(9):1136-1142.

10. Lassalle A, Thomaré P, Fronteau C, et al. Home administration of bortezomib in multiple myeloma is cost-effective and is preferred by patients compared with hospital administration: results of a prospective single-center study. Ann Oncol. 2016;27(2):314-318.

11. Leleu X, Mateos M-V, Delforge M. Assessment of Multiple Myeloma Patient Preferences on Treatment Choices: An International Discrete Choice Study. Blood. 2015;126(23):2086.

12. Reed Johnson F, Lancsar E, Marshall D, et al. Constructing experimental designs for discrete-choice experiments: report of the ISPOR Conjoint Analysis Experimental Design Good Research Practices Task Force. Value Health. 2013;16(1):3-13.

13. Hüttl Maack V, Helm R, Steiner M. A customer-based approach for selecting attributes and levels for preference measurement and new product development. Int J Product Devel. 2016;21(4):233.

14. Janssen EM, Marshall DA, Hauber AB, Bridges JFP. Improving the quality of discrete-choice experiments in health: how can we assess validity and reliability? Expert Rev Pharmacoecon Outcomes Res. 2017;17(6):531-542. 


\section{Supplementary materials}

Details regarding conducted targeted literature review

Date of literature search: 21 March 2016

Inclusion criteria:

- Article written in English.

- Article published during the last 10 years (related to the time of conducting the literature search).

- Answering the research question of the study.

Search strings as entered in PubMed:

"RRMM AND DCE," "Multiple AND myeloma AND DCE," "Multiple AND myeloma AND Discrete choice experiment," "relapsed AND refractory AND multiple AND myeloma AND discrete choice experiment," "RRMM AND discrete choice experiment," "relapsed refractory multiple myeloma AND treatment," "RRMM AND treatment," "attribute AND oncology AND preference," "attribute AND cancer AND preference," "relapsing refractory multiple myeloma AND ixazomib," "RRMM AND ixazomib," "discrete choice experiment AND oncology," "discrete choice experiments AND Onkologie," "discrete choice experiments AND Multiple Myelom," "DCE AND Oncology AND cancer," "oncology AND dce AND preference," "oncology AND dce AND treatment," "dce AND Multiple Myeloma."

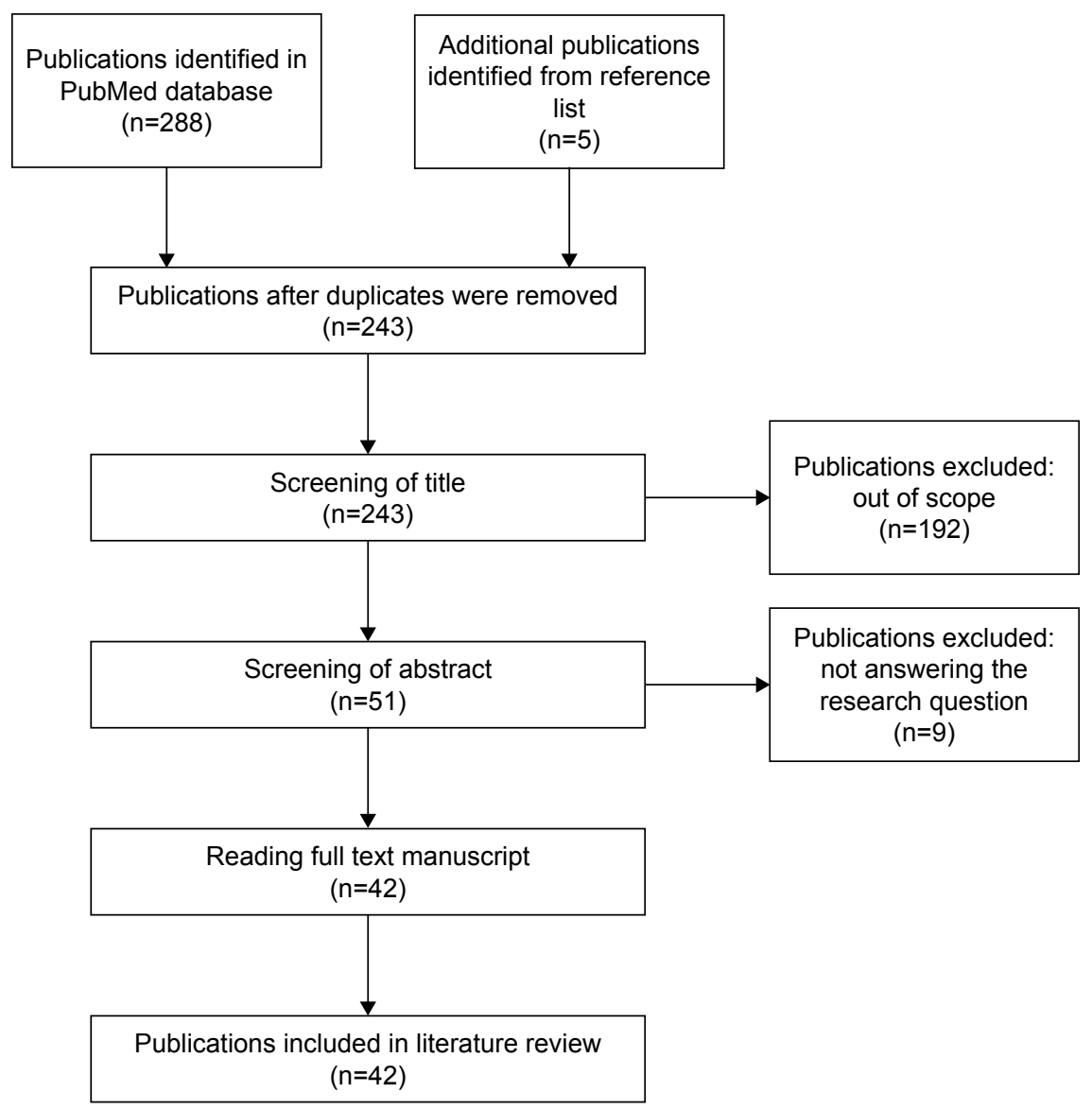

Figure SI The PRISMA flowchart illustrating the publication selection process. 
Table SI Relative importance of different treatment attributes in defined RRMM patient

\begin{tabular}{|c|c|c|c|c|c|c|c|c|}
\hline \multirow[t]{2}{*}{ Attributes } & \multicolumn{2}{|c|}{$\begin{array}{l}\text { Relative } \\
\text { importance, } \\
\text { expressed in \% } \\
\text { for "Gender" }\end{array}$} & \multicolumn{2}{|c|}{$\begin{array}{l}\text { Relative importance, } \\
\text { expressed in \% for "Age" }\end{array}$} & \multicolumn{2}{|c|}{$\begin{array}{l}\text { Relative importance, } \\
\text { expressed in \% for } \\
\text { "Disease duration" }\end{array}$} & \multicolumn{2}{|c|}{$\begin{array}{l}\text { Relative } \\
\text { importance, } \\
\text { expressed in \% } \\
\text { for "Distance } \\
\text { to treating } \\
\text { physician" }\end{array}$} \\
\hline & $\begin{array}{l}\text { Male } \\
(n=53)\end{array}$ & $\begin{array}{l}\text { Female } \\
(n=3 I)\end{array}$ & $\begin{array}{l}\leq 63.5 \text { years } \\
(n=42)\end{array}$ & $\begin{array}{l}>63.5 \text { years } \\
(n=42)\end{array}$ & $\begin{array}{l}\leq 4.18 \text { years } \\
(n=42)\end{array}$ & $\begin{array}{l}>4.18 \text { years } \\
(n=42)\end{array}$ & $\begin{array}{l}\leq 15 \mathrm{~km} \\
(\mathrm{n}=45)\end{array}$ & $\begin{array}{l}>15 \mathrm{~km} \\
(\mathrm{n}=39)\end{array}$ \\
\hline Therapy regimen/drug administration & $39.20 * *$ & $39.25 * *$ & $37.66 * *$ & $40.07^{* *}$ & $38.43 * *$ & $39.32 * *$ & $35.44 * *$ & $42.4 I * *$ \\
\hline Time without progression of disease & $35.55^{* *}$ & $43.20^{* *}$ & $42.32^{* *}$ & $35.21 * *$ & $39.75^{* *}$ & $37.38^{*}$ & $38.73^{* *}$ & $38.95^{* *}$ \\
\hline $\begin{array}{l}\text { Possibility of side effects affecting } \\
\text { the blood }\end{array}$ & 8.38* & $8.47^{*}$ & 4.64 & $12.00 *$ & $6.78^{\#}$ & $10.60 *$ & $10.04 *$ & $7.04^{\#}$ \\
\hline Possibility of side effect heart failure & $16.86 * *$ & $9.08 * *$ & $15.37^{* *}$ & $12.73 * *$ & $15.04 * *$ & $12.70 * *$ & $15.79 * *$ & $11.59 * *$ \\
\hline Decision & 100.00 & 100.00 & 100.00 & 100.00 & 100.00 & 100.00 & 100.00 & 100.00 \\
\hline
\end{tabular}

Notes: Significance levels: ${ }^{*} P<0.001 ; * P<0.05$; $* P<0.10$ (significance of the respective attribute within the conditional logit model). This table gives an overview of the importance of treatment attributes for different patient. Separate conditional logit regression models were estimated for each of the presented subgroups. Threshold: median.

Abbreviation: RRMM, relapsed refractory multiple myeloma

Table S2 Utilities for different hypothetical possible treatment options, expressed in months of progression-free survival that patients would be willing to trade

\begin{tabular}{|c|c|c|c|c|c|c|c|c|}
\hline \multicolumn{3}{|c|}{ Therapy regimen/drug administration } & \multicolumn{2}{|c|}{$\begin{array}{l}\text { Possibility of } \\
\text { side effects } \\
\text { affecting the } \\
\text { blood }^{\mathrm{a}}\end{array}$} & \multicolumn{2}{|c|}{$\begin{array}{l}\text { Possibility of } \\
\text { side effect } \\
\text { heart failure }\end{array}$} & \multirow[t]{2}{*}{$\begin{array}{l}\text { Utility (expressed in } \\
\text { months of PFS patients } \\
\text { would be willing to } \\
\text { trade) }\end{array}$} & \multirow[t]{2}{*}{ Rank } \\
\hline Application $\mathrm{I}^{\mathrm{b}}$ & Application $2^{c}$ & Application $3^{\mathrm{d}}$ & $12 \%$ & $19 \%$ & $2 \%$ & $4 \%$ & & \\
\hline \multirow[t]{2}{*}{$x$} & & & $x$ & & $x$ & & 14.44 & 1 \\
\hline & $\mathrm{X}$ & & $x$ & & $x$ & & 12.94 & 2 \\
\hline$x$ & & & & $x$ & $x$ & & 12.52 & 3 \\
\hline \multirow[t]{3}{*}{$x$} & & & $x$ & & & $x$ & 11.13 & 4 \\
\hline & $x$ & & & $x$ & $x$ & & 11.02 & 5 \\
\hline & $x$ & & $x$ & & & $x$ & 9.63 & 6 \\
\hline \multirow[t]{6}{*}{$x$} & & & & $x$ & & $x$ & 9.21 & 7 \\
\hline & $x$ & & & $\mathrm{x}$ & & $x$ & 7.71 & 8 \\
\hline & & $x$ & $x$ & & $x$ & & 5.22 & 9 \\
\hline & & $x$ & & $x$ & $x$ & & 3.31 & 10 \\
\hline & & $x$ & $x$ & & & $x$ & 1.92 & 11 \\
\hline & & $x$ & & $x$ & & $x$ & 0.00 & 12 \\
\hline
\end{tabular}

Notes: ${ }^{\text {TTh }}$ attribute includes thrombocytopenia, neutropenia, anemia, and hypokalemia. ${ }^{b}$ Application I describes the following therapy regimen/drug application: "oral intake once daily and once per week; physician visit once per month with a duration of approximately 2 hours; patient does not need to be accompanied." 'Application 2 describes the following therapy regimen/drug application: "oral intake once daily and twice per week; physician visit once per month with a duration of approximately 2 hours; patient does not need to be accompanied." 'Application 3 describes the following therapy regimen/drug application: "oral intake once daily and once per week; physician visit twice per week, including administration of one infusion per visit, with a duration per visit of $\sim 3-4$ hours; patient needs to be accompanied." This table shows the results of the estimation of the patients' utilities for different combinations of the three treatment-describing attributes application, side effects affecting the blood, and side effect heart failure. In the table, the negative utility associated with a shorter progression-free survival (PFS) time was translated into a "willingness to accept" this shorter time to receive a treatment with more favorable attributes regarding administration regimen and side effect profile.

Patient Preference and Adherence

\section{Dovepress}

\section{Publish your work in this journal}

Patient Preference and Adherence is an international, peer-reviewed, open access journal that focuses on the growing importance of patient preference and adherence throughout the therapeutic continuum. Patient satisfaction, acceptability, quality of life, compliance, persistence and their role in developing new therapeutic modalities and compounds to optimize clinical outcomes for existing disease states are major areas of interest for the journal. This journal has been accepted for indexing on PubMed Central. The manuscript management system is completely online and includes a very quick and fair peer-review system, which is all easy to use. Visit http://www. dovepress.com/testimonials.php to read real quotes from published authors. 